\title{
Laser ablation ICP-MS for simultaneous quantitative imaging of iron and ferroportin in hippocampus of human brain tissues with
}

Alzheimer's disease

María Cruz-Alonso, ${ }^{1}$ Beatriz Fernandez, ${ }^{1} *$ Ana Navarro, ${ }^{2}$ Susana Junceda, ${ }^{3}$ Aurora Astudillo, ${ }^{3}$ Rosario Pereiro ${ }^{1}$

${ }^{1}$ Department of Physical and Analytical Chemistry, Faculty of Chemistry, University of Oviedo, Julian Claveria 8, 33006 Oviedo, Spain.

${ }^{2}$ Department of Morphology and Cell Biology, Faculty of Medicine, University of Oviedo, Julian Claveria 6, 33006 Oviedo, Spain.

${ }^{3}$ Service of Anatomo-pathology, Hospital Universitario Central de Asturias - HUCA. Av Roma s/n, 33011 Oviedo, Spain.

*Author to whom correspondence should be addressed:

fernandezbeatriz@uniovi.es 


\begin{abstract}
Laser ablation inductively coupled plasma - mass spectrometry (LA-ICP-MS) is proposed for a better understanding of metals and proteins distribution in micrometre structures of human brain tissues. Simultaneous absolute quantitative imaging of $\mathrm{Fe}$ and ferroportin (FPN), in $5 \mu \mathrm{m}$ thick tissue sections of the stratum pyramidale of hippocampus CA1 region, was carried out for Alzheimer disease (AD) patients and healthy controls (HC). For the imaging of FPN by LA-ICP-MS, antibodies were labelled via carbodiimide crosslinking with fluorescent gold nanoclusters (AuNCs) of $2.2 \mathrm{~nm}$ diameter, enabling a high amplification (314 gold atoms per NC). Laboratory made gelatin standards containing $\mathrm{Fe}$ and $\mathrm{Au}$ were used for LA-ICP-MS calibration. Results showed that iron presents an increased concentration in AD donors compared with HC donors, whereas similar concentrations of FPN in AD donors with respect to HC donors were obtained. The average absolute FPN concentrations in selected areas obtained with the proposed AuNCs method were compared with the levels obtained by densitometric analysis with a traditional IHC approach, observing a similar trend in all cases.
\end{abstract}

KEYWORDS: Ferroportin; Alzheimer's disease; Iron accumulation; Gold nanoclusters; Quantitative bioimaging; Laser ablation ICP-MS. 


\section{INTRODUCTION}

Alzheimer's disease (AD) is characterised by cerebrovascular and neuronal dysfunction leading to a progressive decline in cognitive functions and the development of dementia. The ethology of AD remains to be clarified, but growing lines of evidence indicate that metal induced oxidative stress plays a pivotal role in AD pathogenesis [1]. Although essential for cell function, increased Fe levels can promote oxidative damage to which the brain is especially vulnerable [2]. Much remains to be learned about the mechanisms responsible for Fe uptake, transport, and export across the blood-brain barrier and within brain parenchyma, however it is known that the identification and characterization of membrane Fe transporter proteins may provide new insights into these processes. In this context, ferritin and transferrin Fe regulatory proteins were found to be dysfunctional and abnormally distributed in the $\mathrm{AD}$ brain, potentially contributing to the reactive mismanagement of normal metabolic pathways [3,4]. Other protein, ferroportin (FPN) can also affect to the Fe homeostasis. FPN is a protein with a transporter function, exporting the Fe from the inside of the cells to the circulation. Thus, it would be important to know the distribution at the same location of both FPN and $\mathrm{Fe}$ in brain structures. Raha et al. [5] have reported a study about the FPN distribution in different brain regions by western blotting of protein lysates, chromogenic immunohistochemistry (IHC) and immunofluorescence using human brain and APP transgenic mice tissues. FPN was localised in pyramidal neurons and no significant changes in levels of FPN was observed by western blotting of brain tissues (cortex including hippocampus and dentate gyrus) from control and transgenic mice.

Imaging elemental analytical techniques with spatial resolution in the low $\mu \mathrm{m}$ range are today of crucial interest in life science studies to achieve a deeper understanding of the role of metals in biological systems (e.g. to know the accumulation of metals in selected regions and to compare the differences of the element distribution between non-pathogenic and pathogenic tissues) [6]. Laser ablation (LA) coupled to inductively coupled plasma - mass spectrometry (ICP-MS) has already demonstrated a great potential for spatially resolved analysis of metals in biological samples [7-9]. Concerning brain tissues, several authors reported images of Fe distribution by LA-ICPMS from healthy control (HC) samples and from affected by neurodegenerative pathologies (e.g. Alzheimer, Parkinson or Wilson's disease) using mouse models [1013]. Hare et al. [14] have recently showed quantitative images of Fe in AD and HC sections from human brain (frontal cortex sections). Experimental results showed that 
while Fe levels (in the range of 10-20 $\mu \mathrm{g} \mathrm{g}^{-1}$ ) in white matter did not differ significantly between experimental groups (HC and AD), Fe was significantly increased in the grey matter of the AD frontal cortex.

LA-ICP-MS allows also the imaging of biomolecules. Maps of specific proteins can be obtained in biological tissues after an IHC protocol with metal-labelled antibodies, constituting an interesting alternative to commonly used fluorescence or chromogenic detection [15-18]. The combination of IHC with LA-ICP-MS presents advantages such as higher multiplexing and potential absolute quantification capabilities. Hutchinson et al. [19] reported the imaging of $\beta$-amyloid protein by LAICP-MS from the brain of a transgenic mouse model of Alzheimer's disease based on measurement of labelled (Eu/Ni) monoclonal antibodies. More recently, Hare et al. [20] examined the co-localization of Fe and the enzyme involved in dopamine biosynthesis in the rodent midbrain.

Although several studies can be found nowadays in the literature related to the imaging of biomolecules by LA-ICP-MS, most of them only collect qualitative distributions of sought proteins. In this context, we have recently proposed the use of small metal nanoclusters (NCs) with fluorescent properties as elemental labels for specific and absolute quantitative imaging of proteins in biological tissues by LA-ICPMS [21,22]; considering that each NC has several hundreds of metal atoms, a high signal amplification in LA-ICP-MS measurements can be achieved. Therefore, these metal NCs offer possibilities for multimodal imaging (through fluorescence and MS analysis) in the same tissue section. Absolute quantitative images of a specific protein by LA-ICP-MS were first obtained using AuNCs labels and the distribution of metallothioneins (MTs) along the retina region in human ocular tissue sections was used as illustration [22].

Concerning brain tissues, previous studies reported changes in the hippocampus of $\mathrm{AD}$ patients [23]. In order to get more information about that region, our research interest was focussed on the simultaneous quantitative imaging of $\mathrm{Fe}$ and FPN concentrations in $\mathrm{AD}$ and $\mathrm{HC}$ human brain sections. Particularly, the stratum pyramidale of hippocampus CA1 was selected as the model region for the study since it has been previously seen neuronal density changes in AD [23]. For the specific localization of FPN, we have first developed an IHC procedure based on the use of AuNCs bioconjugated with the specific primary antibody (Ab) via carbodiimide crosslinking (in addition, an improved AuNCs synthesis procedure is presented to 
obtain AuNCs with higher size homogeneity as compared to those previously employed for MT1/2 in ocular tissues). The proposed method was applied to $4 \mathrm{HC}$ and $4 \mathrm{AD}$ human brain tissues as a proof of concept. In addition, the FPN absolute quantitative distribution obtained by the proposed LA-ICP-MS method was compared to FPN localization provided by conventional IHC and densitometric analysis [24].

\section{EXPERIMENTAL SECTION}

\section{Reagents and Materials}

For the synthesis of AuNCs, $\mathrm{NaAuCl}_{4} \cdot \mathrm{H}_{2} \mathrm{O}$ (99\% powder; Sigma-Aldrich, San Luis, USA), lipoic acid (> 98\% powder; Across Organics, Geel, Belgium), propan-2-ol (Fisher Scientific, Hampton, USA) and $\mathrm{NaBH}_{4}$ (> 98\% powder, Sigma-Aldrich) were employed.

Immunoassays in the brain tissue sections for LA-ICP-MS were performed with a primary polyclonal anti-human SLC-40A1/Ferroportin-1 Ab produced in rabbit (LSBio, Seattle, USA). 1-ethyl-3-(3-dimethylaminopropyl) carbodiimide (EDC) (98\% powder; Across Organics) and N-hydroxysuccinimide (NHS) (95\% powder; Thermo Fisher Scientific, Waltham, MA, USA) were used in the Ab labelling procedure. To reduce non-specific interactions, hydroxylamine hydrochloride ( $\geq 99 \%$ powder; Sigma-Aldrich) was used [21]. Amicon ultra centrifugal filter units (10 and $100 \mathrm{kDa}$ pore size, Millipore, Burlington, USA) were used for purification. Concerning traditional IHC, biotinylated horse universal antibody (Vector laboratories, Burlingame, USA), extravidin (Sigma-Aldrich) and Sigma Fast DAB (Sigma-Aldrich) were used for chromogenic IHC detection.

Target retrieval solution, pH 9 (10x), (3-in-1) (Agilent Technologies, Santa Clara, CA, USA) was used for antigen retrieval and ammonium chloride (Panreac AppliChem, Barcelona, Spain) to minimize tissue autofluorescence. Triton X-100 (Sigma-Aldrich) was employed to permeabilize tissue sections, and bovine serum albumin (BSA) (99\% powder) and goat serum were employed as blocking agents, both from Sigma-Aldrich. Washing steps in the immunoassay were done with phosphate buffered saline solution (PBS, 10 mM, pH 7.4) (Sigma-Aldrich). 4',6-diamidino-2 phenylindole dihydrochloride (DAPI) (Thermo Fisher Scientific) was used to stain the cell nucleus. Mounting media specific for fluorescence detection (Agilent Technologies) was employed to protect the tissue during microscopy visualization. 
For the calibration by LA-ICP-MS, laboratory standards of gelatin (Merck, Darmstadt, Germany) were prepared. $\mathrm{NaAuCl}_{4} \cdot \mathrm{H}_{2} \mathrm{O}$ and $\mathrm{FeSO}_{4} \cdot 7 \mathrm{H}_{2} \mathrm{O}(99 \%$ powder; Panreac AppliChem) were used for $\mathrm{Au}$ and Fe calibration, respectively. $65 \% \mathrm{HNO}_{3}$ (w/w) Suprapur (EMD Millipore) and $\mathrm{H}_{2} \mathrm{O}_{2}$ (Merck) were employed for acidic digestion of gelatin standards for conventional nebulization ICP-MS analysis. All solutions were prepared with distilled deionized water $\left(18.2 \mathrm{M} \Omega . \mathrm{cm}^{-1}\right)$ from a Milli-Q water purification system (Millipore).

\section{Instrumentation}

LA-ICP-MS analyses were carried out with a commercial LA system (LSX-213 from Teledyne Cetac Technologies, Omaha, USA) coupled to a double-focusing sector field ICP-MS (Element 2, Thermo Fisher Scientific, Bremen, Germany) working at medium mass resolution mode to remove polyatomic interferences of the sought isotopes (particularly important for ${ }^{40} \mathrm{Ar}^{16} \mathrm{O}$ interference from ${ }^{56} \mathrm{Fe}$ ). The commercial ablation cell of LSX-213 system was replaced by a Peltier-cooled ablation chamber built in-house with a reduced internal volume that allows keeping sample temperature constant at $-20{ }^{\circ} \mathrm{C}$ [25]. LA-ICP-MS coupling was daily optimised using SRM NIST 612 glass standard for high sensitivity, background intensity, and the ${ }^{238} \mathrm{U} /{ }^{232} \mathrm{Th}$ signal ratio that should be close to $1 .{ }^{248} \mathrm{ThO} /{ }^{232} \mathrm{Th}$ signal ratio was also measured for controlling oxide formation, being always below $0.5 \%$ at the selected conditions.

Brain tissue sections were ablated in scanning mode using a laser beam diameter of $10 \mu \mathrm{m}$. Overlapping laser spots and high repetition rates result in a differential scanning mode, so that a lateral resolution better than the selected laser spot diameter was achieved [26]. Samples were ablated line by line under optimized LA-ICP-MS conditions summarised in Table S1 (Supporting Information). In all cases, human brain sections were scanned with the laser beam using an average of 70-80 single lines. For imaging data treatment, the gas blank contribution was eliminated from the raw intensity signals to work with net intensities. Two-dimensional images obtained by LAICP-MS were created using ImageJ-Fiji software (National Institute of Health, Bethesda, USA). A magnification of the image was applied with a six factor with respect to the real size of the image ( $\mu \mathrm{m}$ dimensions) and a bicubic interpolation was done to eliminate the pixel aspect. 
Fluorescent images for the optimisation of the IHC protocol were obtained with a laser confocal microscope (DM IRE2; Leica, Wetzlar, Germany) with a 40x oil immersion objectives and using a photomultiplier and a hybrid detector. Laser excitation line of $405 \mathrm{~nm}$ (for bioconjugate and DAPI measurements) was employed. Image processing was carried out with ImageJ software. Additionally, optical images of human brain tissue sections submitted to traditional IHC were done by optical transmission microscopy (Olympus BX61, digital camera Olympus DP-70, Tokio, Japan). Adobe Photoshop CS 8.0.1 (Adobe Systems Inc., CA, USA) was used for quantification of the chromogenic signal and density was measured by ImageJ-Fiji software.

\section{Experimental Protocols}

Synthesis of AuNCs and labelling of anti-human Ferroportin-1. AuNCs were synthesized following a procedure described elsewhere [27], but with a slight modification that allowed to improve their size homogeneity. Briefly, $30 \mu \mathrm{mol}$ of lipoic acid was dissolved in $20 \mathrm{~mL}$ of deionized water with $50 \mu \mathrm{L}$ of $2 \mathrm{M} \mathrm{NaOH}$ in a light protected vial. Then, $200 \mu \mathrm{L}$ of $50 \mathrm{mM} \mathrm{AuCl}{ }_{4} \mathrm{Na} \cdot \mathrm{H}_{2} \mathrm{O}$ (1:3 final ratio of Au:ligand) was added. After $5 \mathrm{~min}$ of stirring, $400 \mu \mathrm{L}$ of the $\mathrm{NaBH}_{4}$ solution dissolved in isopropanol $(50 \mathrm{mM})$ was added to the vial dropwise. The reaction was kept at room temperature with constant stirring for $15 \mathrm{~h}$. The excess of ligand and reductant was removed by ultrafiltration (10 kDa pore size Amicon ultra centrifugal filter units).

Labelling of the $\mathrm{Ab}$ was carried out following a protocol described for determination of MTs in ocular tissues [22]. A 1:3 molar ratio of Ab:AuNCs in the labelling solution was used as the optimum value. Furthermore, anti-human SLC40A1/Ferroportin-1-AuNCs was incubated with hydroxylamine hydrochloride (in a 1:100 AuNCs:hydroxylamine molar ratio) to reduce nonspecific interactions. To determine the available $\mathrm{Ab}$ concentration in the $\mathrm{Ab}-\mathrm{AuNCs}$ biomolecule, an ELISA was performed with a mouse IgG protein standard produced with a known concentration in "The Biotechnology Preparative" Unit of the Scientific-Technical Services (University of Oviedo).

Collection of human brain tissues from post mortem donors. Formalin fixed and paraffin embedded AD $(n=4)$ and $\mathrm{HC}(\mathrm{n}=4)$ human brain tissues from hippocampus were provided by the Asturias Principality Brain Bank and obtained from necropsies 
within $6 \mathrm{~h}$ of death. Table 1 collects details of $\mathrm{AD}$ and $\mathrm{HC}$ human brains. In the case of $\mathrm{AD}$, Braak stages are indicated.

The pieces from human hippocampus were fixed by immersion in $10 \%$ formalin in 0.1 phosphate buffer ( $\mathrm{pH}$ 7.4) for neuropathological diagnosis and IHC studies. After fixation, they were washed in distilled water, dehydrated through successive alcohols, cleared in 2 baths of butyl acetate, embedded in paraffin, and placed in a suitable mould. $5 \mu \mathrm{m}$ thick transverse sections were attached to FLEX coated microscope slides (IHC Microscope slides, Agilent Technologies). Such slides were incubated for $60 \mathrm{~min}$ at 56 ${ }^{\circ} \mathrm{C}$ and afterwards immersed in the 3-in-1 solution for target retrieval $(\mathrm{pH} 9)$ at $95{ }^{\circ} \mathrm{C}$ for 20 min (the 3-in-1 procedure prior to IHC performs deparaffinization, re-hydration and target retrieval in one step). Two parallel sections for each sample were subsequently submitted to the corresponding immunoassay protocol depending on the study: (i) conventional chromogenic IHC using DAB staining for optical microscopy evaluation and densitometric analysis, and (ii) the proposed IHC protocol with AuNCs for LA-ICP-MS imaging.

Immunoassay protocol for LA-ICP-MS analyses. After deparaffinization of human brain sections, tissues were washed three times (10 min) with $10 \mathrm{mM}$ PBS pH 7.4 and, subsequently, incubated with $0.1 \%$ triton X-100 in PBS (5 min). Next, another sequence of washing steps with PBS (10 min, three times) was performed and the slides were then incubated with the blocking agent solution $(0.1 \%$ BSA and $10 \%$ goat serum solution in $10 \mathrm{mM}$ PBS, $\mathrm{pH}$ 7.4) at room temperature for $30 \mathrm{~min}$. Subsequently, Ab (5 $\mu \mathrm{g} \cdot \mathrm{mL}^{-1}$ ) labelled with AuNCs was added and incubated overnight at $4{ }^{\circ} \mathrm{C}$. After the incubation, a final washing step with PBS was done and the slides were stored at $-20{ }^{\circ} \mathrm{C}$ until LA-ICP-MS analysis. For optimization steps of this immunoassay protocol with AuNCs labels, AuNCs fluorescence detection was employed. In this case, after the washing step with PBS, the tissue was incubated for $10 \mathrm{~min}$ at room temperature in darkness with DAPI solution, to stain the cell nucleus. Finally, they were immersed in fluorescence mounting media and a cover glass was added. The same tissue slide can be sequentially analysed both by fluorescence and, after removing the mounting media, by LA-ICP-MS.

Preparation of laboratory gelatin standards for quantitative LA-ICP-MS measurements. Quantitative distribution of FPN (through Au signal from AuNCs label) 
and Fe by LA-ICP-MS was studied using laboratory gelatin standards. Preparation of laboratory standards is collected in the Supporting Information.

Conventional immunohistochemistry and determination of FPN in human brain tissue sections by densitometric analysis. After deparaffinization of human brain tissue sections, an IHC protocol with diaminobenzidine (DAB) staining was carried out in parallel sections of $\mathrm{AD}$ and $\mathrm{HC}$ samples for evaluation of FPN expression. A detailed description of conventional IHC procedure and operations followed to determine FPN content in $\mathrm{AD}$ and $\mathrm{HC}$ samples by densitometric analysis are collected in Supporting Information.

\section{RESULTS AND DISCUSSION}

Synthesis and characterization of AuNCs used as elemental labels for bioimaging studies

Metallic NCs have been previously employed as labels for imaging studies of proteins both by fluorescence and LA-ICP-MS measurements. Particularly, AuNCs composed of 579 gold atoms (on average) have been successfully used for imaging of MT1/2 and MT3 in ocular tissue sections [21]. These labels provide high signal amplification as elemental tags for LA-ICP-MS and offer the possibility to perform absolute quantitative measurements of protein distribution [22]. AuNCs employed in our previous studies exhibited a particle diameter of $2.7 \pm 0.1 \mathrm{~nm} \quad(\mathrm{n}=200,99 \%$ confidence intervals obtained with the standard normal distribution). Such standard deviation in the AuNCs diameter is directly related to the number of Au atoms per NC and, therefore, to the protein concentration. In such way, the synthesis of AuNCs with smaller particle size distribution will allow obtaining more precise and accurate determinations of protein by LA-ICP-MS.

In this work, a modification was included in the AuNCs synthesis compared to the previously employed [27]: water was replaced by isopropanol for dissolving the reductant reagent $\left(\mathrm{NaBH}_{4}\right)$. As reported by other authors for the synthesis of nanoprims, the change in the solvent can produce a more homogeneous particle size $[28,29]$. Synthesised AuNCs were characterized by HR-TEM and Fig. 1a shows the morphological study of purified AuNCs. In this case, AuNCs have a particle diameter of 
$2.2 \pm 0.04 \mathrm{~nm}(\mathrm{n}=200,99 \%$ confidence intervals obtained with the standard normal distribution). Therefore, AuNCs with a lower diameter as well as with a better size homogeneity were synthesized by using isopropanol. As collected in Fig. 1b, crystalline structure of the material was checked by the pattern of selected area diffraction (SAED). Face-centred cubic structure of $\mathrm{Au}$ atoms was found, similar to that reported for the previous AuNCs synthesis [27].

Determination of the AuNCs concentration (i.e., number of AuNCs in a given volume) was also carried out for the new synthesis. The amount of $\mathrm{Au}$ present in the AuNCs suspensions was determined by conventional nebulization ICP-MS in three solutions: a solution containing the synthesis precursor $\left(\mathrm{NaAuCl}_{4} \cdot \mathrm{H}_{2} \mathrm{O}\right)$, the AuNCs purified solution, and the filtered solution collected during the purification process. Au concentration in the purified AuNCs solution was $0.49 \mathrm{mM}$. Furthermore, a mass balance (expressed in Au moles) was calculated to obtain the synthesis molar yield, which turned out to be $91 \pm 4 \%$ (previous AuNCs synthesis exhibited $72 \pm 3 \%$ molar yield). Thus, not only the homogeneity of AuNCs was improved but also the molar yield. Following calculation procedures reported for the first synthesis with data obtained by HR-TEM [27], it was determined that each AuNC is composed by an average of $314 \mathrm{Au}$ atoms. Subsequently, combining the Au molar concentration in the AuNCs suspension obtained by ICP-MS and the calculated moles of Au atoms per NCs (1 NC contains $5.21 \cdot 10^{-19}$ moles of $\mathrm{Au}$ ), it was possible to determine that the AuNCs particle concentration in the purified solution is $9.4810^{14} \mathrm{NCs} \mathrm{mL}^{-1}$.

\section{Optimization of the immunohistochemistry procedure for FPN} determination in biological tissues using AuNCs

Optimization of the IHC procedure for FPN determination with AuNCs as labels was initially carried out using fluorescence detection of AuNCs because fluorescence measurements are typically cheaper and faster than conventional LA-ICP-MS analyses. However, it should be stated that in brain tissue sections high autofluorescence signals can be found due to age-related accumulation of yellow-brown (lipofuscin) or other pigments (e.g. ceroid). In our samples, lipofuscin accumulates with age in the cytoplasmin postmitotic cells (such as neurons), limiting the correct measurement of the fluorescence signal from the AuNCs bioconjugate for FPN [30]. Although there are treatments to reduce this autofluorescence signal, these treatments also reduce the intensity of immunofluorescent labelling [31]. To check the lipofuscin fluorescence in 
the hippocampus CA1 region of the tissues, a control IHC was carried out (without AuNCs bioconjugate). As can be seen in Fig. S1 (Supporting Information), high fluorescence signals were observed at the stratum pyramidale of hippocampus CA1 region. Therefore, brain tissue sections were discarded for optimization procedures by fluorescence detection following AuNCs emission. Intestine tissues from $\mathrm{HC}$ samples were selected for optimisation steps since it is well-known the FPN distribution in the intestinal basolateral membrane [32]. Furthermore, it is expected to find a higher content of FPN in intestine compared to brain tissues, allowing an easier optimisation (higher signals).

For optimum IHC analysis with AuNCs as labels it is necessary to consider that after bioconjugation of anti-human SLC-40A1/Ferroportin-1 Ab with AuNCs, the surface of the AuNCs still contains activated carboxyl groups which did not react with the $\mathrm{Ab}$. Thus, it is necessary to block such remaining functional groups to avoid nonspecific interaction with biomolecules in the tissue section, which can subsequently produce a high background signal after the IHC procedure. For such purpose, hydroxylamine was investigated as blocking agent at different molar ratios (1:20, 1:100 and 1:200). Three parallel intestine tissue sections were used to check the optimum molar ratio excess of hydroxylamine: $1: 20,1: 100$ and 1:200 molar ratio of AuNCs:hydroxylamine. In all cases, $5 \mu \mathrm{m}$ tissue sections were subjected to IHC protocol for fluorescence detection using the Ab labelled with AuNCs $\left(5 \mu \mathrm{g} \mathrm{mL}^{-1} \mathrm{Ab}\right.$ concentration) previously incubated with hydroxylamine. Fig. 2 shows the localization of FPN in the intestinal basolateral membrane obtained by laser confocal microscopy (following AuNCs emission) using 1:20, 1:100 and 1:200 molar ratio excess of hydroxylamine (Fig. 2a, 2b and 2c, respectively). It can be observed that the fluorescence signal was low and unspecific in the case of 1:20 molar ratio (Fig. 2a), whereas fluorescence signal significantly decreased for 1:200 molar ratio (Fig. 2c). In contrast, 1:100 molar ratio (Fig. 2b) shows a correct FPN distribution along the intestinal basolateral membrane and it was selected to study FPN distribution in biological tissues. Fig. S2 (Supporting Information) shows the LA-ICP-MS image after such IHC protocol. 


\section{Quantitative imaging of Fe and FPN in AD and HC brain tissue sections by}

\section{LA-ICP-MS}

$5 \mu \mathrm{m}$ thick sections of $\mathrm{AD}$ and $\mathrm{HC}$ human brain tissues were ablated using experimental conditions collected in Table S1 (Supporting Information). Two dimensional images covering an area of hippocampus (CA1 region which can be visualized with the visor of LA system) were obtained for FPN $\left({ }^{197} \mathrm{Au}^{+}\right.$signal from AuNCs label) and Fe. AD's neuropathological hallmarks such as neurofibrillary tangles appear firstly in the transentorhinal region (stage I) followed by the CA1 region of the hippocampus (stage II) [33]. As an example, Fig. 3 shows the qualitative 2D images obtained for FPN and Fe distribution in the stratum pyramidale of hippocampus CA1 region after LA-ICP-MS analysis of an AD human brain tissue section (Fig. 3c and 3d, respectively). As can be seen, enough sensitivity was obtained for studying the distribution of both Fe and FPN. On microscopic assessment of inmunostained brain slides (Fig. 3a), the neurons of stratum pyramidale express FPN in the AD tissue (the distribution pattern in neurons is similar in HC and AD) and the staining was light and confined to the soma. Interestingly, FPN exhibited a different distribution into the analysed region compared to Fe, which was mainly present outside the CA1.

Concerning the analysis of metals, previous studies reported that formalin fixation may affect absolute metals concentrations due to possible losses during paraffin embedding [34]; however, this type of sample preparation is preferably required for immunoassays protocols. It should be also noted that Gellein et al. [35] reported that storage in formalin for short periods ( $<18$ months) was shown to have no effect on brain Fe levels. In addition, the different steps required for the immunoassay and bioconjugation with the AuNCs proposed method may produce leaching of metals from the tissue sections. In this context, the possible effect on the Fe content of the antigen retrieval procedure employed for IHC was investigated. For such purpose, three parallel tissue sections from the same donor (AD \#7) were analysed by LA-ICP-MS after different sample treatments: without any IHC procedure (the measurement was done directly with the FFPE tissue section), after xylol treatment, and after target retrieval at pH 9. Fig. 4 shows the 2D qualitative images obtained by LA-ICP-MS for ${ }^{56} \mathrm{Fe}^{+}$at the hippocampus of brain tissues analysed without any IHC and after xylol treatment (Fig. $4 \mathrm{a}$ and $4 \mathrm{~b}$, respectively). Fig. $3 \mathrm{~d}$ collects the ${ }^{56} \mathrm{Fe}^{+}$image obtained for the same donor using the antigen retrieval protocol. As can be observed, similar ${ }^{56} \mathrm{Fe}^{+}$intensities were exhibited in all cases with the same metal distribution; so, the used IHC procedure does 
not produce noticeable Fe losses. Furthermore, it should be highlighted that with the proposed method it is possible to observe all the $\mathrm{Fe}$ in the brain structures, whereas traditional methods generally provide information just about the labile Fe [36].

In order to compare the distribution of Fe and FPN along the hippocampus region of $\mathrm{AD}$ and $\mathrm{HC}$ human brain tissues, Fig. 5 shows the qualitative images obtained by LA-ICP-MS in $2 \mathrm{AD}$ and $2 \mathrm{HC}$ human brain tissues. Also, Fig. S3 in the Supporting Information collects qualitative images from other donors. Specifically, Fig. 5 depicts images from donors \#3, \#4, \#5 and \#7 and Fig. S3 from donors \#1, \#2, \#6 and \#8. To correlate signals from $\mathrm{Fe}$ and FPN at the CA1 region of the same tissue, ${ }^{56} \mathrm{Fe}^{+}$and ${ }^{197} \mathrm{Au}^{+}$signals were overlapped in the same image: Fe distribution can be seen in cyan scale, whereas FPN distribution is shown in purple scale. Fe accumulates in the brain with $\mathrm{AD}$, and iron-induced oxidative stress has been considered as one of the initial causes for AD. A non-homogeneous Fe distribution in the hippocampus was observed in the human brain tissues (both for $\mathrm{HC}$ and $\mathrm{AD}$ ), being $\mathrm{Fe}$ accumulated out of the stratum pyramidale of hippocampus CA1 region (where FPN was mainly distributed). A similar distribution for Fe and FPN was observed for all the donors investigated. Obtained images can allow also distinguishing some peculiarities between donors: for example in Fig. S3c (Supporting Information), single points with an elevated Fe content were seen in the image, which can be attributed to blood vessels in this tissue region (donor \#6 suffered from acute hypoxia).

In contrast to traditional IHC procedures, the here proposed method will allow to study not only the qualitative (signals) distribution of Fe and FPN in human brain tissues with a high sensitivity but also to know their absolute concentration along the different tissue structures. In such way, external calibration was performed based on $\mathrm{Au}$ and Fe standard-spiked gelatin sections [22]. Correction by density differences between gelatin and human brain tissues were taken into account (gelatin density was $1.14 \mathrm{~g} \mathrm{~cm}^{-3}$ and the brain exhibited an average density value of $1.05 \mathrm{~g} \mathrm{~cm}^{-3}$ ). In addition, correction of possible sensitivity drift was performed by measuring the gelatin standards before and after each sample (standard-sample bracketing calibration). Fig. S4 (Supporting Information) shows the calibration curves obtained for $\mathrm{Au}$ and $\mathrm{Fe}$ by plotting the signal intensities obtained by LA-ICP-MS versus the $\mathrm{Au}$ and Fe-standards concentration. A good linearity was observed for both elements: ${ }^{197} \mathrm{Au}$ Intensity $=240.08[\mathrm{Au}]\left(\mathrm{ng} \mathrm{g}^{-1}\right)+$ $202.45\left(\mathrm{R}^{2}=0.999\right)$ and ${ }^{56} \mathrm{Fe}$ Intensity $=154.43[\mathrm{Fe}]\left(\mathrm{ng} \mathrm{g}^{-1}\right)+54.45\left(\mathrm{R}^{2}=0.999\right)$. 
The limit of detection (LOD) for Au and Fe was calculated by using the $3 \mathrm{~s}$ criterion $\left(3 \mathrm{~s}_{\mathrm{b}} / \mathrm{S}\right)$, where $\mathrm{s}_{\mathrm{b}}$ is the standard deviation of 5 independent blank signals (i.e. gelatin standard without $\mathrm{Au}$ and $\mathrm{Fe}$ ) and $\mathrm{S}$ is the element sensitivity obtained in the calibration graph. The LODs was found to be $6.7 \mathrm{ng} \cdot \mathrm{g}^{-1}$ for $\mathrm{Au}$ and $13.4 \mathrm{ng} \cdot \mathrm{g}^{-1}$ for Fe.

Using the linear regression obtained with the gelatin standards (Fig. S4), each data point (or pixel) resulting from the ${ }^{197} \mathrm{Au}^{+}$and ${ }^{56} \mathrm{Fe}^{+}$qualitative images (Fig. 5 and Fig. S3) was converted from net intensities (in cps) into concentrations ( $\mu \mathrm{g} \mathrm{Au} \cdot \mathrm{g}^{-1}$ and $\mu \mathrm{g} \mathrm{Fe} \cdot \mathrm{g}^{-1}$, respectively). As quantitative images of FPN (expressed as $\mu \mathrm{g}$ of FPN per $\mathrm{g}$ of tissue) are our final goal, calculations should be done to convert detected $\mathrm{Au}$ concentration into FPN concentration. First, the number of AuNCs per Ab molecule (stoichiometry) should be calculated (Supporting Information contains details related to such study). Furthermore, following a similar approach to that described previously [22] it was possible to transform $\mathrm{Au}$ concentration (from the AuNC label) into FPN concentration in the human brain tissues. Briefly, Au concentration (expressed as moles $\mathrm{g}^{-1}$ ) in each pixel of the qualitative images was transformed to the corresponding concentration of AuNCs (number AuNCs g ${ }^{-1}$ ) per sample pixel. Afterwards, with the stoichiometry of the bioconjugate (one AuNC per $\mathrm{Ab}$ ), it was possible to know the $\mathrm{Ab}$ concentration (number $\mathrm{Ab} \cdot \mathrm{g}^{-1}$ ) in each sample pixel of the human brain tissue. On the other hand, taking into account a recognition stoichiometry 1:1 (Ab:antigen), the calculation of the FPN concentration in $\mathrm{mol} \mathrm{g}^{-1}$ per sample pixel was possible. Finally, by using the molecular mass of FPN $(\sim 52 \mathrm{kDa})$, moles of FPN can be converted to $\mu \mathrm{g}$, enabling 2D quantitative images of FPN (expressed as $\mu \mathrm{g}$ FPN g ${ }^{-1}$ ) in AD and HC human brain tissues.

As an example, Fig. 6 collects the absolute quantitative images for FPN and Fe distribution (expressed in $\mu \mathrm{g}$ FPN g $\mathrm{g}^{-1}$ and in $\mu \mathrm{g} \mathrm{Fe} \cdot \mathrm{g}^{-1}$, respectively) obtained by LAICP-MS from the hippocampus of HC (Fig. 6a) and AD (Fig. 6b) human brain tissues. In addition, Fig. S5 and Fig. S6 in the Supporting Information depicts the images obtained from other donors (Fig. S5 for HC and Fig. S6 for AD human brain tissues). Some differences observed on FPN and Fe distribution and content along the hippocampus can be attributed to biological diversity characteristics for each individual patient. In the case of $\mathrm{Fe}$, an increase of the metal concentration was observed for AD compared to $\mathrm{HC}$ donors in the region out of the stratum pyramidale of hippocampus CA1. This is in agreement with literature, where it is reported that in Alzheimer's 
disease the rate of $\mathrm{Fe}$ accumulation is more advanced than in controls $[4,14]$. Concerning FPN, no significant changes in FPN maximum concentration was observed from $\mathrm{HC}$ and $\mathrm{AD}$ donors (at the stratum pyramidale of hippocampus $\mathrm{CA} 1$ ).

In order to get information about the average FPN content in the hippocampus region, the arithmetic mean of the protein concentration was calculated for the area marked with red quadrangles in LA-ICP-MS quantitative images (Fig. 6, Fig. S5 and Fig. S6). This region corresponds to the stratum pyramidale of hippocampus CA1 region. Fig. S7 (Supporting Information) collects the average results obtained for each sample of $\mathrm{AD}$ and $\mathrm{HC}$ donors. It should be stated that this average concentration gives only an indicative value since the selected areas (red quadrangles) included regions with high FPN content together with regions without protein (dark blue colour). Thus, more valuable information can be directly extracted from 2D LA-ICP-MS images since absolute FPN (and Fe) concentration is obtained at each single pixel, which could further help to understand biological processes at such $\mu \mathrm{m}$ structures.

The analysis of FPN was finally performed in parallel tissue sections of the human brain samples by conventional IHC. FPN concentrations obtained by LA-ICPMS were compared to levels provided by densitometry (see details in the Experimental section) [24]. Fig. S8 (Supporting Information) collects the optical transmission microscopy images from the samples after traditional IHC protocol with DAB. The same sample area (marked with a red quadrangle in LA-ICP-MS and microscopy images) was always used for evaluation of FPN. As can be seen, the staining in the tissues was light, which can difficult in some cases localization of FPN. Fig. S7 depicts a comparative view of the average values obtained for FPN in the selected areas using the two approaches. It should be highlighted that in the case of the proposed AuNCs method, the average FPN absolute concentration was expressed in terms of $\mu \mathrm{g}$ FPN g ${ }^{-1}$ of tissue, whereas using IHC approach FPN levels can be obtained expressed as densitometric arbitrary units. As can be seen, FPN levels showed a similar trend in the $\mathrm{AD}$ and $\mathrm{HC}$ human brain tissue sections investigated with the two approaches. Additionally, it should be indicated that no significant differences between AD and HC donors, in terms of evolution of the average protein concentration in the stratum pyramidale of hippocampus CA1 region, can be extracted with the medical cases studied $(n=8)$. 


\section{CONCLUSIONS}

One of the problems with conventional IHC approaches is related to the quantitative interpretation of results, which is typically based on relative scoring; therefore, such analyses can be susceptible to inter-observer variability. On the other hand, densitometric analysis just gives level values instead of concentrations. In contrast, LA-ICP-MS detection avoids risks of biased results and, also, opens the door for obtaining absolute concentrations. Other problem that presents densitometric analysis of conventional IHC is related with the measured area: to obtain levels of the specific protein is necessary to work in a high resolution mode (to be able to apply the software treatment). In the case of LA-ICP-MS detection, although the analysis time will increase with the sampled area, it is easier to obtain the concentration from bigger areas $\left(>1.5 \mathrm{~mm}^{2}\right)$ than with the IHC approach.

In this work, AuNCs with 314 gold atoms per AuNC were used to label the $\mathrm{Ab}$ in order to achieve amplified detection of FPN by LA-ICP-MS; moreover, these AuNCs are fluorescent, thus allowing for a cheaper optimization of the IHC procedure. Quantitative images of FPN after an IHC procedure with AuNCs as labels and of Fe were obtained in a region of the hippocampus of human brain tissue sections. The proposed format with the AuNCs labelled Ab and LA-ICP-MS detection made possible to obtain in the same tissue section simultaneous absolute quantification of total Fe and the protein.

To finish, it is worth to highlight that the IHC format used in the LA-ICP-MS bioimaging (primary Ab labelled with metal NCs) opens the door to the development of highly multiplexed protein analysis using NCs of different metals (such as Ag or Pt). In addition, isotopically enriched metal $\mathrm{NCs}$ can be synthesized to increase the multiplexing capabilities.

\section{Compliance with ethical standards}

The present study was conducted according to the Declaration of Helsinki and was approved by "Comité Ético de Investigación Clínica Regional del Principado de Asturias" as follows. These studies were granted waivers of consent on the following bases: (i) samples were gathered retrospectively from pathology archives of necropsies performed for diagnostic purposes; (ii) patient identities were anonymized and completely delinked from unique identifiers; and (iii) there was no risk to the participants. 


\section{Conflict of interest}

There are no conflicts to declare.

\section{Acknowledgements}

This work was supported through project CTQ2016-79015-R by Agencia Estatal de Investigación (Spain) and FEDER and by FISS Instituto de Salud Carlos III though the project (PI15/00601) (co-funded by European Regional Development Fund/European Social Fund "Investing in your future"). B. Fernandez acknowledges her contract RYC-2014-14985 to the Spanish Ministry of Economy and Competitiveness through the "Ramón y Cajal Program". Authors thank Vanesa Ramírez for help during the first LA-ICP-MS analysis and María Daniela Corte (HUCA) for her support with IHC procedures. 


\section{REFERENCES}

[1] P.I. Moreira, A. Nunomura, M. Nakamura, A. Takeda, J.C. Shenk, G. Aliev, M.A. Smith, G. Perry, Nucleic acid oxidation in Alzheimer disease, Free Radic. Biol. Med. 44 (2008) 1493-1505.

[2] E.P. Raven, P.H. Lu, T.A. Tishler, P. Heydari, G. Bartzokis, Increased iron levels and decreased tissue integrity in hippocampus of Alzheimer's disease detected in vivo with magnetic resonance imaging, J. Alzheimers Dis. 37 (2013) 127-136.

[3] J.R. Connor, B.S. Snyder, J.L. Beard, R.E. Fine, E.J. Mufson, Regional distribution of iron and iron-regulatory proteins in the brain in aging and Alzheimer's disease, J. Neurosci. Res. 31 (1992) 327-335.

[4] W.-Y. Ong, A.A. Farooqui, Iron, neuroinflammation, and Alzheimer's disease, J. Alzheimers Dis. 8 (2005) 183-200.

[5] A.A. Raha, R.A. Vaishnav, R.P. Friedland, A. Bomford, R. Raha-Chowdhury, The systemic iron-regulatory proteins hepcidin and ferroportin are reduced in the brain in Alzheimer's disease, Acta Neuropathol. Commun. 1 (2013) 55.

[6] M. Montes-Bayón, M. Sharar, M. Corte-Rodriguez, Trends on (elemental and molecular) mass spectrometry based strategies for speciation and metallomics, Trends in Anal. Chem. 104 (2018) 4-10.

[7] A. Sussulini, J.S. Becker, J.S. Becker, Laser ablation ICP-MS: application in biomedical research, Mass Spectrom. Rev. 36 (2017) 47-57.

[8] D. Pozebon, G.L. Scheffler, V.L. Dressler, Recent applications of laser ablation inductively coupled plasma mass spectrometry (LA-ICP-MS) for biological sample analysis: a follow-up review, J. Anal. At. Spectrom. 32 (2017) 890-919.

[9] A. Sajnóg, A. Hanć, D. Barałkiewicz, Metrological approach to quantitative analysis of clinical samples by LA-ICP-MS: A critical review of recent studies, Talanta 182 (2018) 92-110.

[10] A. Matusch, C. Depboylu, C. Palm, B. Wu, G.U. Höglinger, M.K-H. Schäfer, J.S. Becker, Cerebral bioimaging of $\mathrm{Cu}, \mathrm{Fe}, \mathrm{Zn}$, and $\mathrm{Mn}$ in the MPTP mouse model of Parkinson's disease using laser ablation inductively coupled plasma mass spectrometry (LA-ICP-MS), J. Am. Soc. Mass Spectrom. 21 (2010) 161-171.

[11] D.J. Hare, J.K. Lee, A.D. Beavis, A. van Gramberg, J. George, P.A. Adlard, D.I. Finkelstein, P.A. Doble, Three-dimensional atlas of iron, copper, and zinc in the mouse cerebrum and brainstem, Anal. Chem. 84 (2012) 3990-3997. 
[12] S.G. Boaru, U. Merle, R. Uerlings, A. Zimmermann, S. Weiskirchen, A. Matusch, W. Stremmel, R. Weiskirchen, Simultaneous monitoring of cerebral metal accumulation in an experimental model of Wilson's disease by laser ablation inductively coupled plasma mass spectrometry, BMC Neurosci. 15 (2014) 98.

[13] L. Feng, J. Wang, H. Li, X. Luo, J. Li, A novel absolute quantitative imaging strategy of iron, copper and zinc in brain tissues by Isotope Dilution Laser Ablation ICP-MS, Anal. Chim. Acta 984 (2017) 66-75.

[14] D.J. Hare, E.P. Raven, B.R. Roberts, M. Bogeski, S.D. Portbury, C.A. McLean, C.L. Masters, J.R. Connor, A.I. Bush, P.J. Crouch, P.A. Doble, Laser ablationinductively coupled plasma-mass spectrometry imaging of white and gray matter iron distribution in Alzheimer's disease frontal cortex, NeuroImage 137 (2016) 124-131.

[15] L. Mueller, A.J. Herrmann, S. Techritz, U. Panne, N. Jakubowski, Quantitative characterization of single cells by use of immunocytochemistry combined with multiplex LA-ICP-MS, Anal. Bioanal. Chem. 409 (2017) 3667-3676.

[16] D.P. Bishop, N. Cole, T. Zhang, P.A. Doble, D.J. Hare, A guide to integrating immunohistochemistry and chemical imaging, Chem. Soc. Rev. 47 (2018) 3770-3787.

[17] M. Cruz-Alonso, A. Lores-Padín, E. Valencia, H. González-Iglesias, B. Fernández, R. Pereiro, Quantitative mapping of specific proteins in biological tissues by laser ablation-ICP-MS using exogenous labels: aspects to be considered, Anal. Bioanal. Chem. (2018) https://doi.org/10.1007/s00216-018-1411-1.

[18] C.R. Taylor, R.M. Levenson, Quantification of immunohistochemistry-issues concerning methods, utility and semiquantitative assessment II, Histopathology 49 (2006) 411-424.

[19] R.W. Hutchinson, A.G. Cox, C.W. McLeod, P.S. Marshall, A. Harper, E.L. Dawson, D.R. Howlett, Imaging and spatial distribution of $\beta$-amyloid peptide and metal ions in Alzheimer's plaques by laser ablation-inductively coupled plasma-mass spectrometry, Anal. Biochem. 346 (2005) 225-233.

[20] D.H. Hare, P. Lei, S. Ayton, B.R. Roberts, R. Grimm, J.L. George J.L., P. Bishop, A.D. Beavis, S.J. Donovan, G. McColl, I. Volitakis, C.L. Masters, P.A. Adlard, R.A. Cherny, A.I. Bush, D.I. Finkelstein, P.A. Doble, An iron-dopamine index predicts risk of parkinsonian neurodegeneration in the substantia nigra pars compact, Chem. Sci. 5 (2014) 2160-2169. 
[21] M. Cruz-Alonso, B. Fernandez, L. Álvarez, H. González-Iglesias, H. Traub, N. Jakubowski, R. Pereiro, Bioimaging of metallothioneins in ocular tissue sections by LA-ICPMS using bioconjugated gold nanoclusters as specific tags, Microchim. Acta 185 (2018) 64.

[22] M. Cruz-Alonso, B. Fernandez, M. Garcia, H. Gonzalez-Iglesias, R. Pereiro, Quantitative imaging of specific proteins in the human retina by laser ablation ICPMS using bioconjugated metal nanoclusters as labels, Anal. Chem. 90 (2018) 12145-12151. [23] E. Martínez-Pinilla, C. Ordóñez, E. del Valle, A. Navarro, J. Tolivia Regional and gender study of neuronal density in brain during aging and in Alzheimer's disease, Front. Aging Neurosci. 8 (2016) 213.

[24] J. Tolivia, A. Navarro, E.D. Valle, C. Perez, C. Ordonez, E. Martínez, Application of photoshop and Scion image analysis to quantification of signals in histochemistry, immunocytochemistry and hybridocytochemistry, Anal. Quant. Cytol. Histol. 28 (2006) $43-53$.

[25] I. Konz, B. Fernández, M.L. Fernández, R. Pereiro, A. Sanz-Medel, Design and evaluation of a new Peltier-cooler laser ablation cell with on-sample temperature control, Anal. Chim. Acta 809 (2014) 88-96.

[26] L. Mueller, H. Traub, N. Jakubowski, D. Drescher, V.I. Baranov, J. Kneipp, Trends in single-cell analysis by use of ICP-MS, Anal. Bioanal. Chem. 406 (2014) 6963-6977.

[27] M. Cruz-Alonso, L. Trapiella-Alfonso, J.M.C. Fernández, R. Pereiro, A. SanzMedel, Functionalized gold nanoclusters as fluorescent labels for immunoassays: Application to human serum immunoglobulin E determination, Biosens. Bioelectron. 77 (2016) 1055-1061.

[28] M. Carboni, L. Capretto, D. Carugo, E. Stulz, X. Zhang, Microfluidics-based continuous flow formation of triangular silver nanoprisms with tuneable surface plasmon resonance, J. Mater. Chem. C 1 (2013) 7540-7546.

[29] D.A. Cristaldi, F. Yanar, A. Mosayyebi, P. García-Manrique, E. Stulz, D. Carugo, $\mathrm{X}$. Zhang, Easy-to-perform and cost-effective fabrication of continuous-flow reactors and their application for nanomaterials synthesis, New biotechnology 47 (2018) 1-7.

[30] B.L. Fletcher, C.J. Dillard, A.L. Tappel, Measurement of fluorescent lipid peroxidation products in biological systems and tissues, Anal. Biochem. 52 (1973) 1-9. 
[31] S.A. Schnell, W.A. Staines, M.W. Wessendorf, Reduction of lipofuscin-like autofluorescence in fluorescently labeled tissue, J. Histochem. Cytochem. 47 (1999) 719-730.

[32] M.T. Núñez, V. Tapia, A. Rojas, P. Aguirre, F. Gómez, F. Nualart, Iron supply determines apical/basolateral membrane distribution of intestinal iron transporters DMT1 and ferroportin 1, Am. J. Physiol., Cell Physiol. 298 (2010) C477-C485.

[33] A. Serrano-Pozo, M.P. Frosch, E. Masliah, B.T. Hyman, Neuropathological alterations in Alzheimer disease, Cold Spring Harb. Perspect. Med. 1 (2011) 1(1): a006189.

[34] I. Konz, B. Fernández, M.L. Fernández, R. Pereiro, A. Sanz-Medel, Laser ablation ICP-MS for quantitative biomedical applications, Anal. Bioanal. Chem. 403 (2012) 2113-2125.

[35] K. Gellein, T.P. Flaten, K.M. Erikson, M. Aschner, T. Syversen, Leaching of trace elements from biological tissue by formalin fixation. Biol. Trace Elem. Res. 121 (2007) $221-225$.

[36] S. Van Duijn, R.J. Nabuurs, S.G. van Duinen, R. Natté, Comparison of histological techniques to visualize iron in paraffin-embedded brain tissue of patients with Alzheimer's disease, J. Histochem. Cytochem. 61 (2013) 785-792. 


\section{FIGURE CAPTIONS}

Figure 1. Morphological study of purified AuNCs by HR-TEM. a) Image showing shape and size of AuNCs, and b) SAED pattern image to obtain the crystalline structure (face-centred cubic structure).

Figure 2. Cellular distribution of FPN in the intestinal basolateral membrane $(5 \mu \mathrm{m}$ tissue sections) in the optimization of IHC procedure with different concentrations of hydroxylamine as blocking agent. Images obtained by laser confocal microscopy (40x). FPN detection with primary Ab anti-human SLC-40A1/Ferroportin labelled with AuNCs. a) Bioconjugate with AuNCs:Hydroxylamine (1:20) (bioconjugate fluorescence), b) Bioconjugate with AuNCs:Hydroxylamine (1:100) (bioconjugate fluorescence), c) Bioconjugate with AuNCs:Hydroxylamine (1:200) (bioconjugate fluorescence), d) Bioconjugate with AuNCs:Hydroxylamine (1:20) (bioconjugate and DAPI fluorescence), e) Bioconjugate with AuNCs:Hydroxylamine (1:100) (bioconjugate and DAPI fluorescence), and f) Bioconjugate with AuNCs:Hydroxylamine (1:200) (bioconjugate and DAPI fluorescence).

Figure 3. Qualitative images obtained by microscopy and LA-ICP-MS for the analysis of an AD human brain tissue after IHC protocols for FPN localization (AD \#7). The region located between the two arrows in all images corresponds to the stratum pyramidale of hippocampus CA1 region. a) Microscopy image obtained for FPN distribution in CA1 region after IHC protocol with DAB staining (peroxidase activity was visualized with Sigma Fast DAB and the sections were counterstained using a modified formaldehyde thionin method, dehydrated, cleared in eucalyptol, and mounted with Eukitt; see Supporting Information). Although better sensitivity can be obtain with 20x images, for comparison purposes with the area analyzed by LA-ICP-MS, 10x image is shown, b) Transmission image obtained for the selected region in the tissue section measured with the camera of the laser system (IHC protocol with Ab-AuNCs), c) Qualitative image obtained by LA-ICP-MS for ${ }^{197} \mathrm{Au}^{+}$(FPN) obtained after IHC with $\mathrm{Ab}$-AuNCs bioconjugate, and d) Qualitative image obtained by LA-ICP-MS for ${ }^{56} \mathrm{Fe}^{+}$ obtained after IHC with Ab-AuNCs bioconjugate. 
Figure 4. ${ }^{56} \mathrm{Fe}^{+}$qualitative images obtained by LA-ICP-MS for an AD human brain tissue sections (AD \#7) following different sample treatments. a) Tissue without any IHC procedure (the measurement was done directly with the FFPE section), and b) Tissue submitted to IHC protocol (with Ab-AuNCs bioconjugate) with xylol treatment.

Figure 5. Qualitative images of ${ }^{56} \mathrm{Fe}^{+}$and ${ }^{197} \mathrm{Au}^{+}$(FPN) distribution obtained by LAICP-MS from the stratum pyramidale of hippocampus CA1 region of $\mathrm{AD}$ and $\mathrm{HC}$ human brain tissues after IHC with AuNC bioconjugate for FPN. Distribution of both elements was overlapped for comparison. a) HC human brain, donor \#3, b) HC human brain, donor \#4, c) AD human brain, donor \#5, and d) AD human brain, donor \#7.

Figure 6. Quantitative images for FPN and Fe distribution (expressed as $\mu \mathrm{g} \mathrm{g}^{-1}$ ) obtained by LA-ICP-MS from the stratum pyramidale of hippocampus CA1 region of human brain tissues after IHC with AuNC bioconjugate for FPN. a) HC human brain, Donor \#4, and b) AD human brain, Donor \#7. 
a)

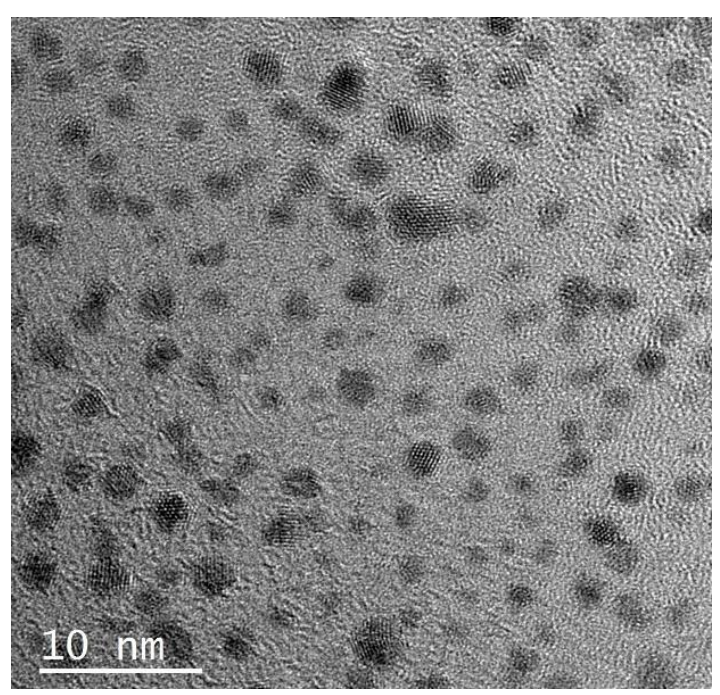

b)

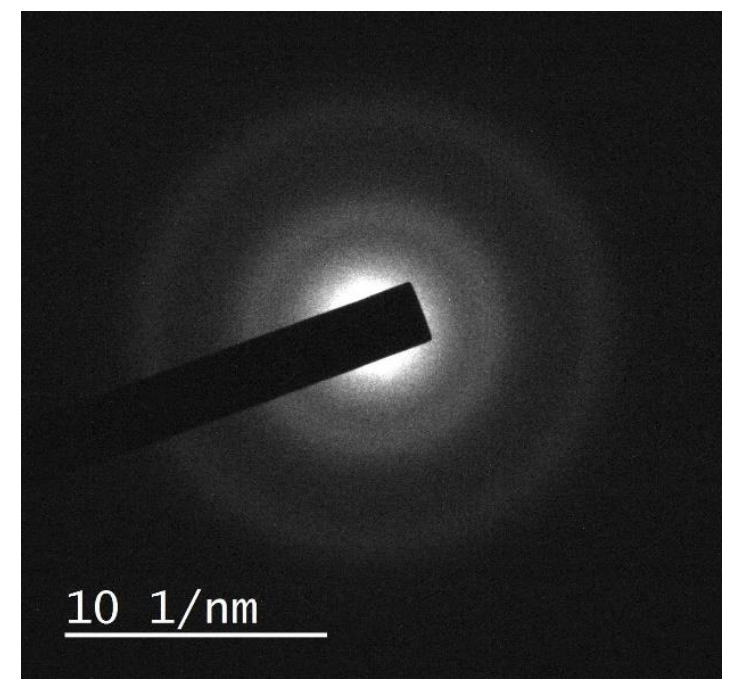

Figure 1 


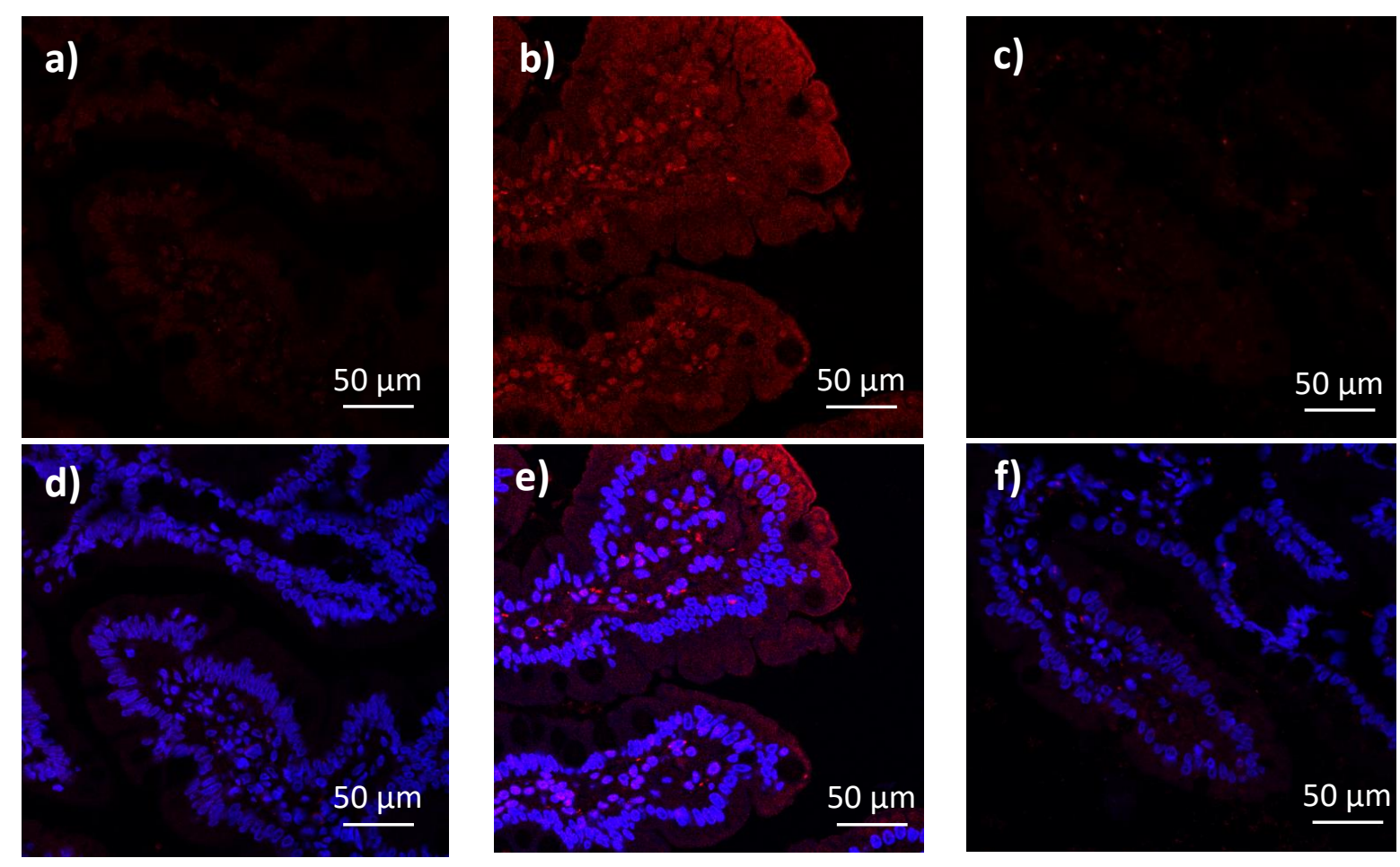

Figure 2 


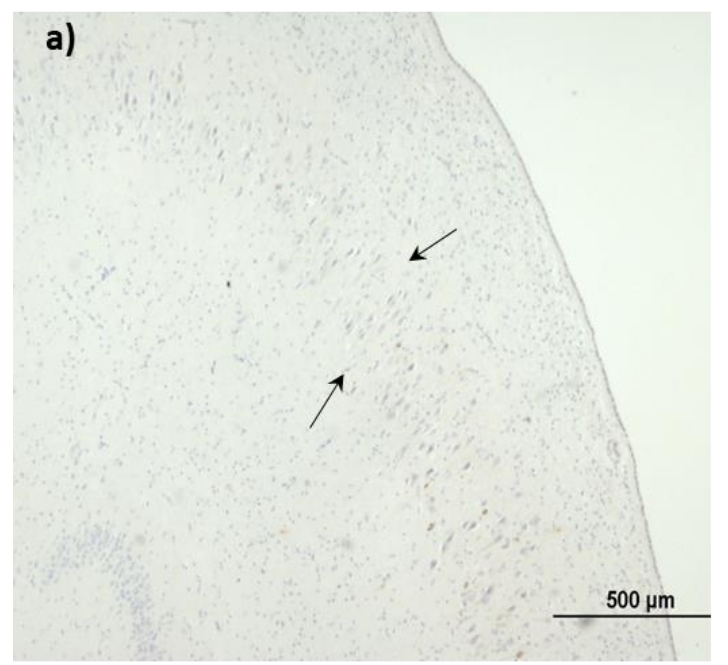

b)

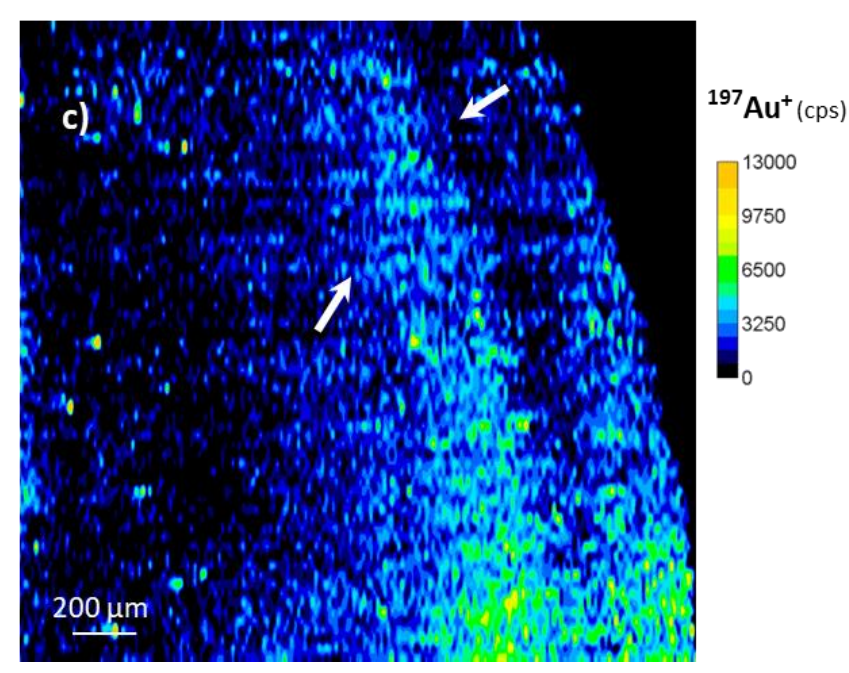

$200 \mu \mathrm{m}$

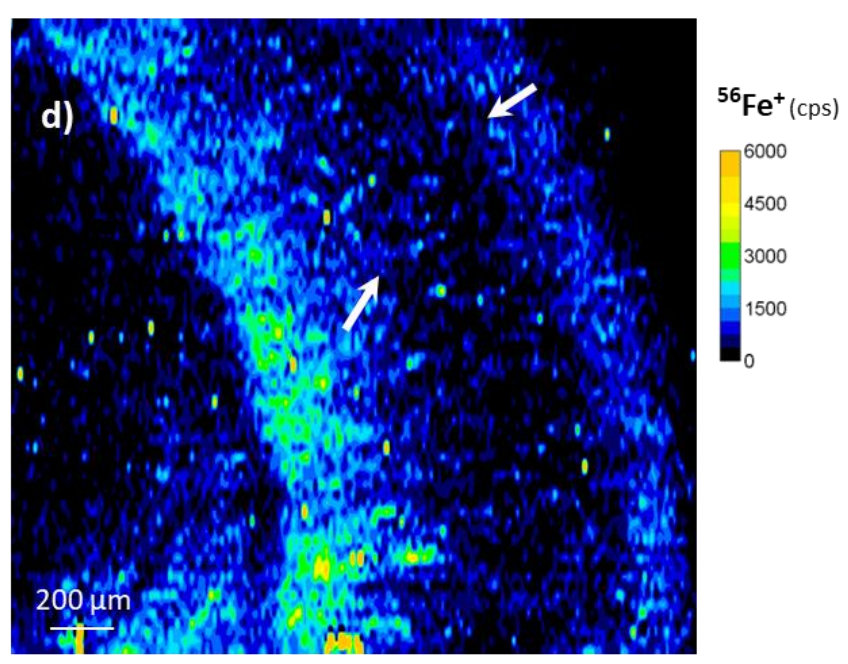

Figure 3 
a)

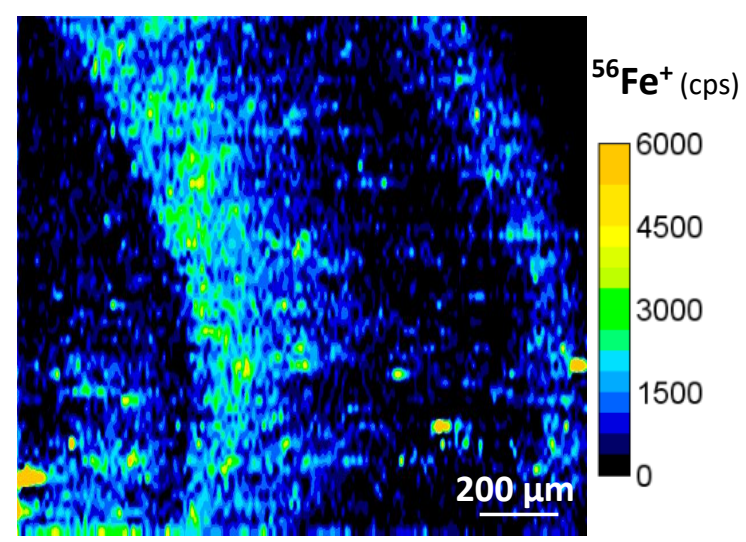

b)

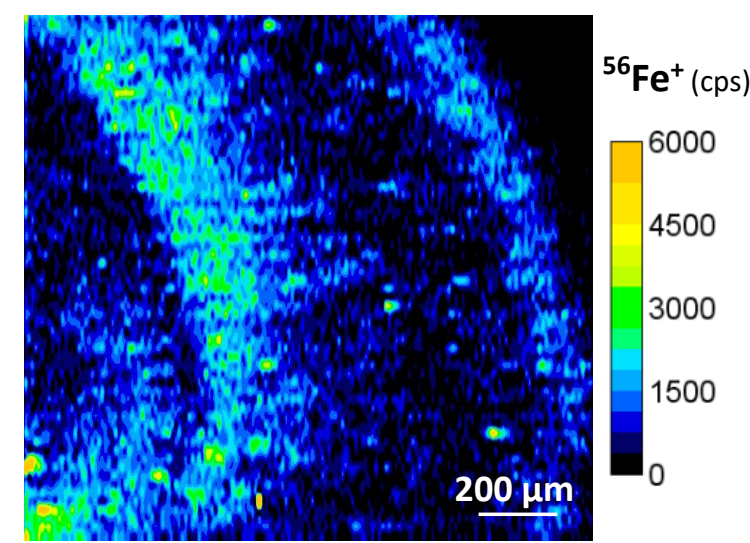

Figure 4 

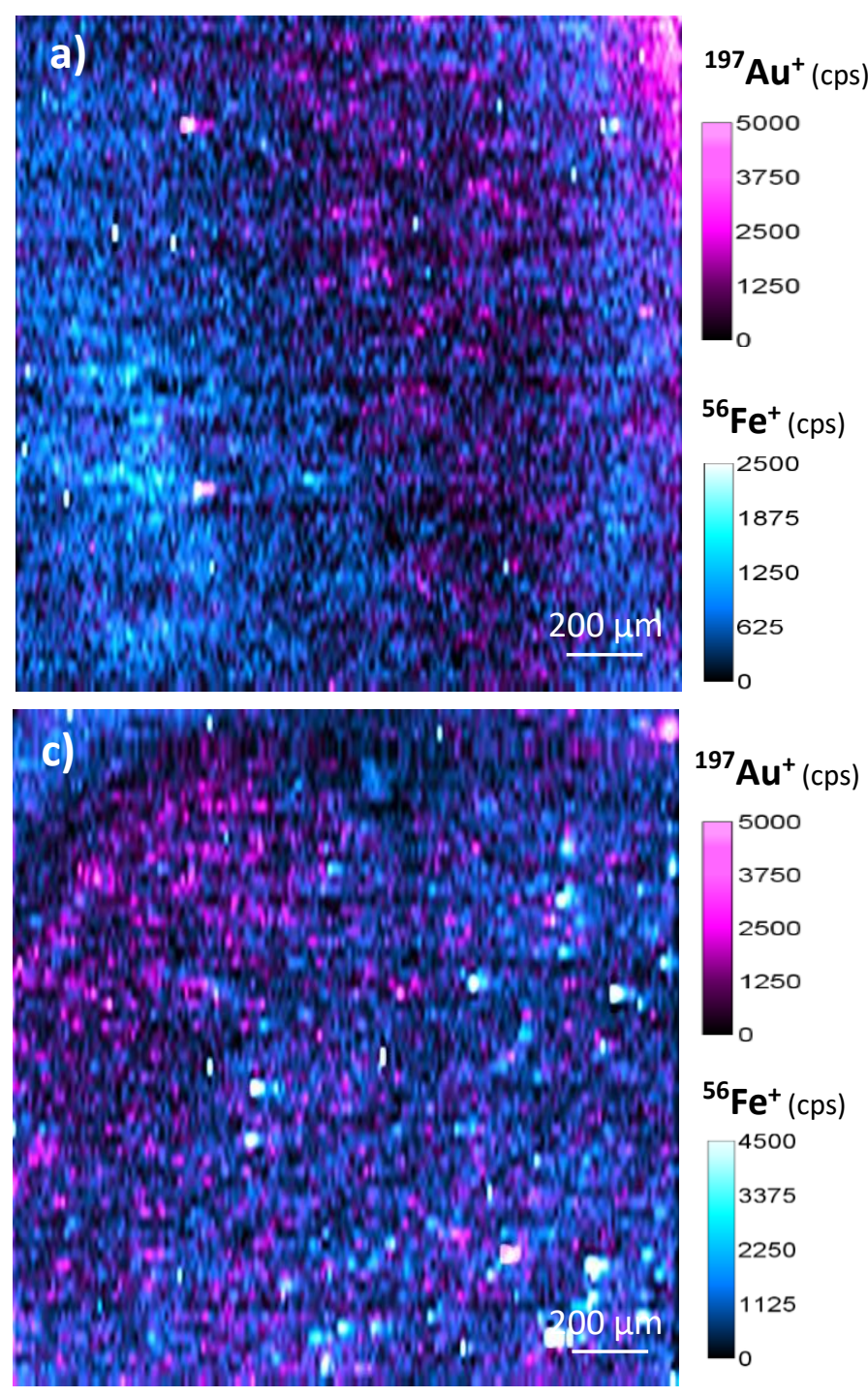
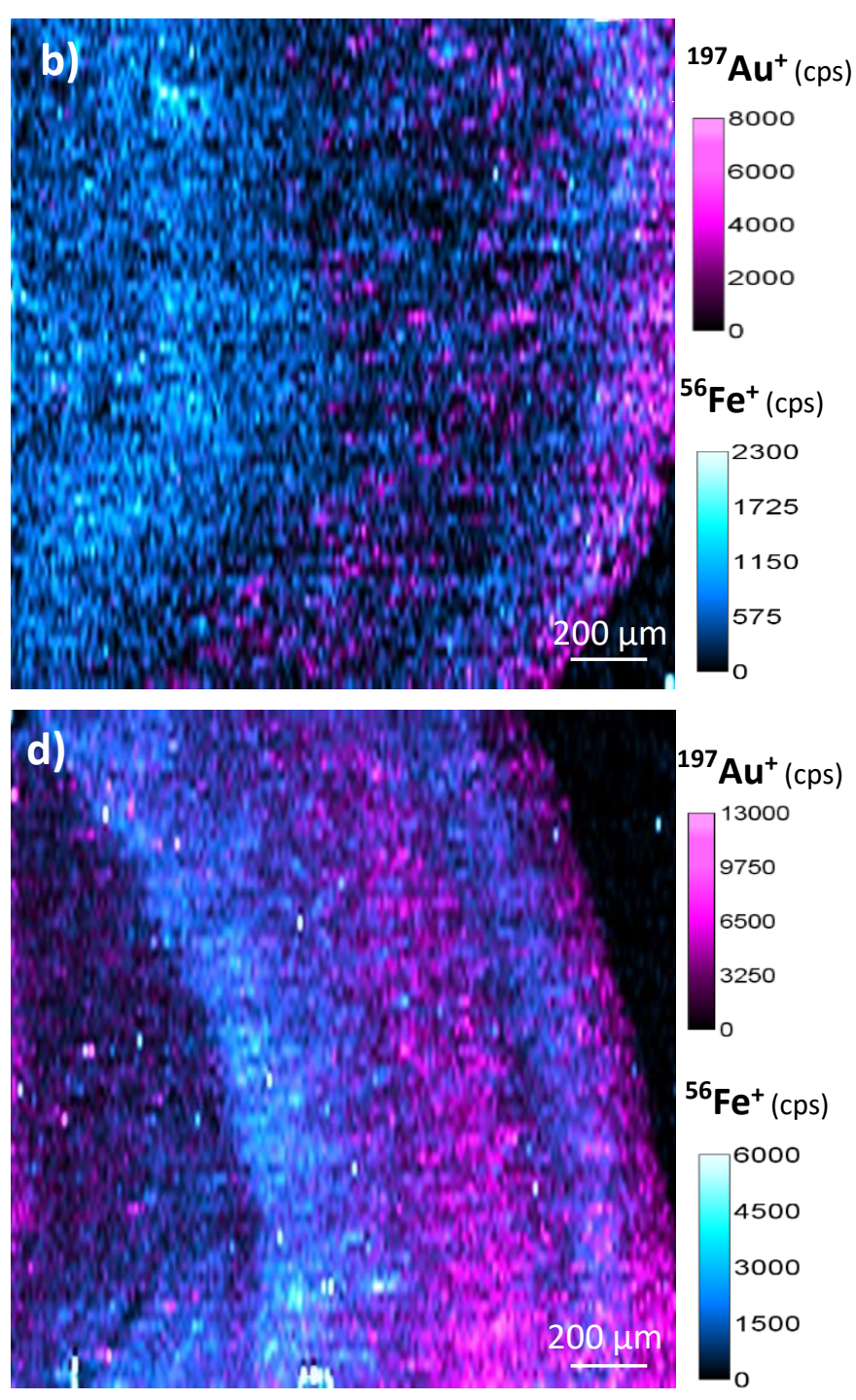

Figure 5 
a)
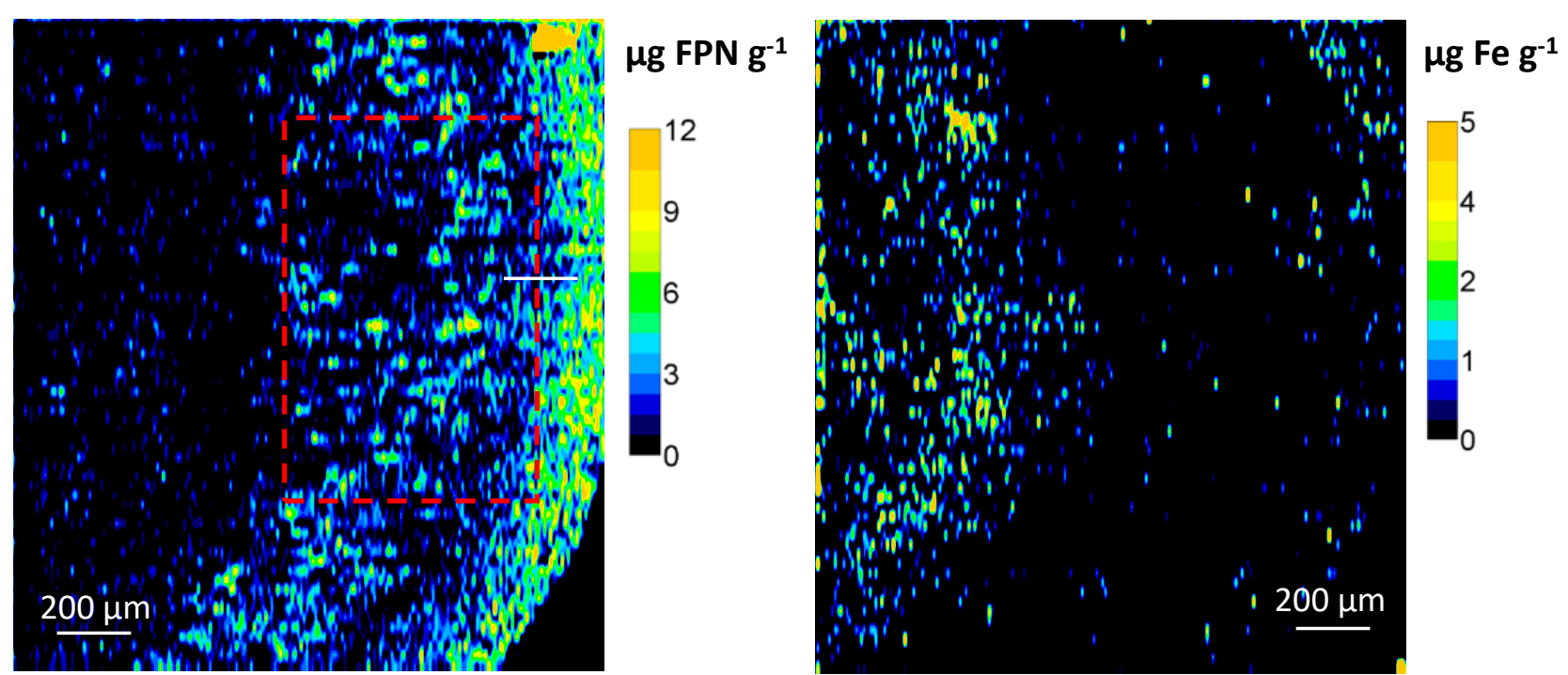

b)
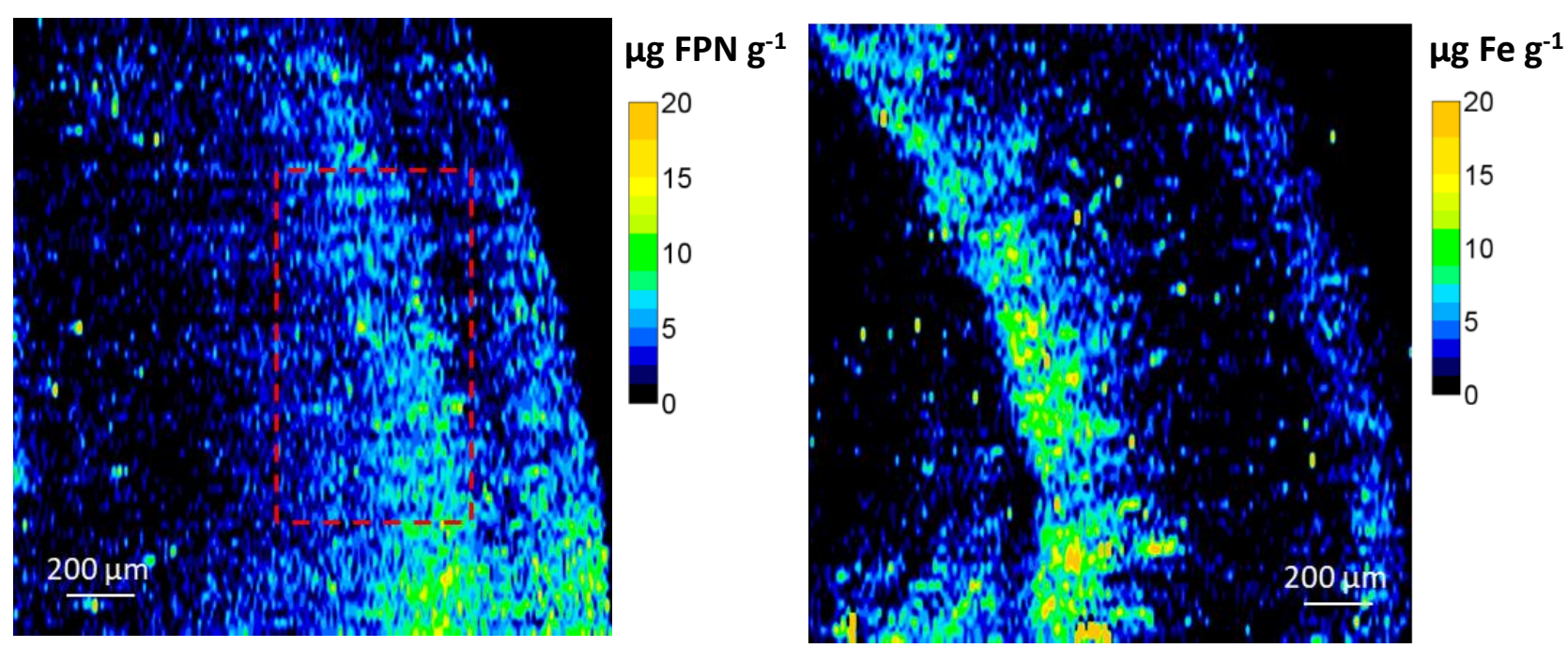

Figure 6 